\title{
Provided visual mediators, imagery instructions, and concreteness in paired associate learning
}

\author{
ELEANOR JORDAN, JERROLD ACKERMAN, and FRANK W. WICKER \\ University of Texas, Austin, Texas 78712
}

\begin{abstract}
Two paired associate lists of 32 nouns were presented to subjects in three treatment conditions: One received imagery instructions, another saw provided pictorial mediators, and the third received only task instructions. Concrete high-imagery-arousing nouns were superior in facilitating learning, especially in the stimulus position. This effect was reduced in the provided-mediator group, as evidenced by an interaction between pair type and treatment, but it was not eliminated. A posttask test of mediator recall presented to the provided-mediator group showed no difference in recall due to pair type if the mediator was recalled, but there were differences in recall of the mediator related to concreteness. The difference between subject-generated and experimenter-provided mediators appeared to depend on the concreteness of materials.
\end{abstract}

It is well established that concreteness (C) and imagery value (I) of words are highly related to recall in paired associate learning (PAL) tasks, especially on the stimulus side, with difficulty increasing in the order: concrete-concrete, concrete-abstract, abstract-concrete, and abstract-abstract (Paivio, 1965, 1971). One explanation for this order is that it is easier to form mediatorial images with concrete words than with abstract words. If so, one should be able to reduce the difference between concrete and abstract words by providing a visual mediator for both types of word, thus eliminating the difference in difficulty of producing a mediator. This expectation was not supported in an experiment by Wollen and Lowry (1971) in which they found no interaction between word imagery and provision of visual mediators, but this lack of support may be specific to the procedures of their study. Silhouettes depicting the pair were shown after the stimulus word, but before the response word of the pair had been shown. The task of relating the specific terms of the provided mediator to the more general terms of the low-I pair may have been rendered somewhat more difficult by this procedure, so that mediators were not as effective for low-I pairs as for high-I pairs.

The present study explored the relationship between imagery use and concreteness by comparing recall of the four pair types by three groups: (1) a group seeing provided mediators along with presentation of the complete pair, (2) a group instructed to image, and (3) a group given only traditional PAL instructions. With these conditions the usual concreteness effect was expected in the imagery-instruction group and in the control group, but this effect was predicted to be much smaller in the provided-mediator group, because the

Requests for reprints should be sent to Frank W. Wicker, Department of Educational Psychology, University of Texas, Austin, Texas 78712 . difficulty of obtaining images with abstract terms would be reduced, if not eliminated.

The relative performance of the provided visual mediator group and the imagery-instruction group was a point of primary interest in the present study. Several recent studies have indicated that self-generated mediators facilitate recall more than provided mediators with adult subjects and with word pairs (e.g., Bower \& Winzenz, 1970). Other studies (e.g., Lieberman, Walters, \& Cox, 1968; Schwartz \& Walsh, 1974) have not found a difference. Paivio $(1971$, p. 313$)$ contrasts two studies which used nonsense syllable-word pairs: Martin and Dean (1966) did not find facilitation for self-generated mediation, whereas Wind and Davidson (1969) did find facilitation with provided mediators. The implication is that, for these learning materials, provided mediation could be shown as superior to self-generated. It is suggested that the relative effectiveness of subject-generated and experimenter-provided mediations will vary with the characteristics of learning materials. As materials become less effective in providing cues for the production of mediators, the relative advantage of provided mediators should increase. In particular, as materials become more abstract the advantage of providing visual mediators should increase.

A postexperimental survey was used to compare the three treatments on reported use of imagery mediation and other learning strategies. Also, the providedmediator group was given an additional test for memory of the pictorial mediators to provide a look at the relationship between response recall and mediator recall.

\section{METHOD}

\section{Subjects}

The subjects were 96 undergraduate students enrolled in an educational psychology class at The University of Texas at Austin. They participated in small groups of one to seven which were assigned in a random order to one of six conditions defined by three treatments and two list orders. 

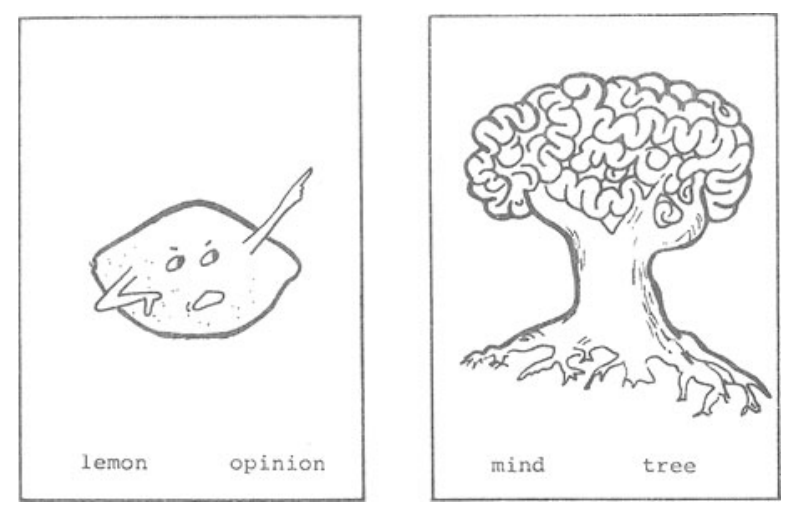

Figure 1. Examples of provided visual mediators.

\begin{abstract}
Materials
Two lists of 16 pairs of nouns were constructed using the list of 925 nouns compiled by Paivio, Yuille, and Madigan (1968). Words were randomly drawn from the list. The first 32 words in the random draw that were high $I$ and high $C$ (defined here as one-half standard deviation above the mean on both scales) were designated as $\mathrm{C}$ words. Likewise, the first 32 words which were one-half standard deviation below the mean on both scales were chosen as $\mathrm{A}$ words. These were then randomly paired to form eight pairs of each type: C-C, C-A, A-C, and A-A. The list was then divided to form two lists with four pairs of each type. For each word pair, a black and white drawing was made depicting the pair in some relationship. For example, vanity-whale was depicted as a whale smiling into a mirror; soul-reminder was represented as a ghost with a string around it's finger. Figure 1 depicts two more examples. Each word pair and drawing was projected from slides on a daylight screen using a projector with a Lafayette repeat-cycle timer.
\end{abstract}

\section{Procedure}

One of three sets of instructions was read to each group of subjects. In addition to the traditional PAL instructions, the group seeing the provided visual mediators (PVM) was told that for each pair a slide would be shown "to help relate the two words of the pair." The group given the imagery instruction set (II) was asked to "form a visual image, that is, a mental picture, to help relate the two words of the pair." The control group was given no instruction beyond an explanation of the PAL task.

Each group was given two trials with each of two lists of 16 pairs. Order of presentation was changed from trial to trial for both the study and the test lists. The study period was $7 \mathrm{sec} /$ pair for the II and control groups. PVM groups saw the word pair for $3.5 \mathrm{sec}$ and then a picture depicting the pair for $3.5 \mathrm{sec}$. The word pair was typed at the bottom of the picture so subjects in all three conditions were exposed to the word pair for the same amount of time.

In all conditions, the stimulus word of each pair was shown for $5 \mathrm{sec}$ and the subject was instructed to write the corresponding response word on the blank side of an IBM card, which he turned face down in order to use the next card for the next pair. In addition, the PVM groups had a picture-mediator recall task. After all study trials and test trials for both lists, the stimulus for each of the 32 pairs was presented and the PVM subjects were given $10 \mathrm{sec} /$ pair in which to write down a phrase of approximately five words describing the picture which had been presented for that pair. Two judges, one of whom was not familiar with the purpose of the study, rated mediator recall from these phrases. There was $90 \%$ agreement on initial judgments and complete agreement after discussion.

After the final test period, all subjects were asked to fill out a card estimating the percentage of time spent using particular methods for remembering the pairs. The four methods listed on the card were verbal association (connecting the items with a sentence, phrase, or common word associate), common element (remembering some element or elements common to the two words), imagery, and repetition.

\section{RESULTS AND DISCUSSION}

Because no significant list effects were found, the data have been collapsed across lists for presentation here. Table 1 shows the mean recall over both trials and both lists for each of four pair types and three training treatments. The expected significant difference in pair type was found $(F=152.91, d f=3 / 279$, $\mathrm{p}<.001$ ), along with the predicted interaction of Pair Type by Condition $(F=2.31$, df $=6 / 279, p<.05)$. The nature of this interaction can be seen at the bottom of Table 1. PVM and II group recall was almost identical for concrete stimulus pairs but PVM recall was higher for abstract stimulus pairs.

This result did not replicate previous findings of greater recall with subject-generated than with experimenter-supplied mediators. It tended to support our suggestion that the relative advantage of provided visual mediators would increase with abstract materials, which was based on an assumption that the effective underlying variables are the number and quality of mediators produced. With easier materials, subjects could self-generate mediators which were effective for them, but did not have time to equal those we provided with more difficult materials. This assumption is consistent with the finding of Schwartz and Walsh (1974) that procedures which equated the particular mediators used in subject-generated and experimenter-supplied conditions also equated recall.

The predicted reduction of differences among pair types in the PVM condition did occur, but while the difference over the whole range was somewhat less for PVM than for the other groups (4.2 as compared to 5.8 and 4.7), this difference was still highly significant $(F=21.09, \mathrm{df}=3 / 124, \mathrm{p}<.01)$. If difference in recall between pair types is due only to ability to produce mediational images and if the provided mediators pro-

Table 1

Mean Pairs Recalled Over Two Trials

\begin{tabular}{cccc}
\multicolumn{3}{c}{ Mean Pairs Recalled Over Two Trials } \\
\hline & $\begin{array}{c}\text { Provided } \\
\text { Visual } \\
\text { Mediators }\end{array}$ & $\begin{array}{c}\text { Imagery } \\
\text { Instructions }\end{array}$ & Control \\
\hline Types of & & & \\
Pairs & & & \\
C-C & 14.0 & 14.6 & 13.5 \\
C-A & 13.0 & 12.5 & 11.4 \\
A-C & 10.9 & 9.8 & 9.0 \\
A-A & 9.8 & 8.8 & 8.8 \\
Types of & & & \\
Stimulus & & & \\
Concrete & 13.5 & 13.6 & 12.5 \\
Abstract & 10.4 & 9.3 & 8.9 \\
\hline
\end{tabular}


Table 2

Recall of Mediators for PVM Condition

\begin{tabular}{ccc}
\hline $\begin{array}{c}\text { Types of } \\
\text { Pairs }\end{array}$ & $\begin{array}{c}\text { Percent of } \\
\text { Mediators } \\
\text { Recalled }\end{array}$ & $\begin{array}{c}\text { Percent Responses } \\
\text { Recalled, Given } \\
\text { Mediator Recall }\end{array}$ \\
\hline C-C & 94.0 & 98.2 \\
C-A & 90.3 & 94.6 \\
A-C & 75.8 & 90.9 \\
A-A & 67.7 & 94.0 \\
\hline
\end{tabular}

duced an effective image for all four pair types, then it would be expected that the PVM group would do equally well on all four types. The fact that our results were consistent with those of Wollen and Lowry (1971) in not showing this requires a closer look at the process. A clue as to why the pair-type difference remained is given by Table 2 , which is based on a distinction between mediator recall (percentage of times mediators were rated as correctly recalled) and mediator effectiveness (percentage of correct response recall given successful mediator recall). The results suggest that there is little systematic differential effect in the second phase (mediator effectiveness), but recall of the provided mediators did show large differences parallel to those obtained for response recall. These data are in keeping with Paivio's conceptual peg hypothesis (1971, p. 247); it appears that, even if we equate the production of mediators on the study trial, there remains a differential effectiveness of concrete and abstract stimuli for cuing recall of mediators on the test trial. An alternate interpretation-that less effective mediators were provided with abstract words-does not receive support from the second column of Table 2. Explanation of this effect is also suggested by Bower (1972): Abstract words evoke imagery only "indirectly through associated concrete words." For instance, in our example a drawing of a ghost is used to represent the stimulus "soul." This would mean that there is an additional difficulty for recall of abstract pairs from an image: A connection must be made from the abstract stimulus to the associated concrete image. Our data do not suggest a comparable difficulty, though, in conncecting a concrete image to an abstract response term.

Table 3 shows the mean percentage reported in each experimental group for each strategy. The finding of some use of imagery in the control group (25.8\%) replicates previous studies (Bower, 1972; Paivio \& Yuille, 1969). Also, the PVM subjects reported significantly more imagery use than the II subjects $(F=9.96$, $\mathrm{df}=1 / 62, \mathrm{p}<.01)$. This is probably due to the inability of the II subjects to produce images for the A pairs. Differences between groups were significant at the .01 level for all strategies except repetition.
Table 3

Mean Percent Reported for Strategies in Each Group

\begin{tabular}{lccc}
\hline & $\begin{array}{c}\text { Provided } \\
\text { Visual } \\
\text { Strategy }\end{array}$ & $\begin{array}{c}\text { Imagery } \\
\text { Mediator }\end{array}$ & $\begin{array}{ccc}\text { Instructions } \\
\text { Control }\end{array}$ \\
\hline Verbal Association & 14.6 & 27.6 & 32.6 \\
Common Element & 4.4 & 8.0 & 14.0 \\
Imagery & 54.9 & 35.5 & 25.8 \\
Repetition & 22.9 & 28.0 & 28.6 \\
\hline
\end{tabular}

The results of this experiment show that imagery can be used to improve recall of abstract pairs as well as of concrete pairs. However, provided pictures did not render recall of abstract pairs equal to recall of concrete pairs. The locus of the remaining differences may be in the retrieval of the image rather than in the effectiveness of the image. Also, an interaction is suggested between stimulus concreteness and the comparison of subjectgenerated and experimenter-provided mediators.

\section{REFERENCES}

Bower, G. H. Mental imagery and associative learning. In L. Gregg (Ed.), Cognition in learning and memory. New York: Wiley, 1972.

Bower, G. H., \& Winzenz, D. Comparison of associative learning strategies. Psychonomic Science, 1970, 20, 119-120.

Lieberman, L. R., Walters, W. M., \& Cox, W. M. Experimenter-mode vs. subject-mode mnemonics in paired-associate learning. Psychological Reports, 1968, 22, 227-231.

Martin, R. B., \& Dean, S. J. Implicit and explicit mediation in paired-associate learning. Journal of Experimental Psychology, 1964, 68, 21-27.

Paivio, A. Abstractness, imagery and meaningfulness in paired-associate learning. Journal of Verbal Learning and Verbal Behavior, 1965, 4, 32-38.

Paivio, A. Imagery and verbal processes. New York: Holt, Rinehart, \& Winston, 1971.

Paivio, A., \& Yuille, J. C. Changes in associative strategies and paired-associate learning over trials as a function of word imagery and type of learning set. Journal of Experimental Psychology, 1969, 79, 458-463.

Paivio, A., Yuille, J. C., \& Madigan, S. A. Concreteness, imagery and meaningfulness values for 925 nouns. Journal of Experimental Psychology Monograph Supplement, 1968, 76(1, Part 2).

Schwartz, M., \& WAlsh, M. F. Identical S-generated and E-provided mediators in paired-associate learning. Journal of Experimental Psychology, 1974, 103, 878-884.

Wind, M., \& Davidson, M. Facilitation of paired-associate learning by language context. Psychonomic Science, 1969, 15, 184-185.

Wollen, K., \& LowRY, D. Effects of imagery on pairedassociate learning. Journal of Verbal Learning and Verbal Behavior, 1971, 10, 276-284.

(Received for publication September 22, 1976.) 